\title{
Influencia del Polimorfismo Inserción / Deleción (rs4646994) del Gen de la Enzima Convertidora de Angiotensina en la Presión Inspiratoria y Espiratoria Máxima de Jóvenes Chilenos Sedentarios
}

\author{
Influence of the Polymorphism Insertion/Deletion (rs4646994) of the Angiotensin Converting Enzyme \\ (ACE) Gene on Maximum Inspiratory and Expiratory Pressure of Chilean Sedentary Youth
}

\author{
Rodrigo Muñoz Cofréí; Sandra Becerra Muñoz ${ }^{2}$ \& Alejandro Pacheco Valles ${ }^{3}$
}

MUÑOZ, C. R.; BECERRA, M. S. \& PACHECO, V. A. Influencia del polimorfismo inserción/deleción (rs4646994) del gen de la enzima convertidora de angiotensina en la presión inspiratoria y espiratoria máxima de jóvenes chilenos sedentarios. Int. J. Morphol., 35(4):1254-1260, 2017.

RESUMEN: La expresión de los genes puede impactar sobre el rendimiento muscular. En este aspecto el polimorfismo del gen de la Enzima Convertidora de Angiotensina (ECA), dependiendo de su inserción (Ins) o deleción (Del) puede potenciar diferentes cualidades musculares. Del mismo modo, si consideramos la ventilación como un proceso vital, sería relevante investigar si existe una influencia de este polimorfismo sobre los músculos que llevan a cabo tan importante función. El objetivo de este trabajo consistió en determinar el rendimiento muscular inspiratorio y espiratorio según alelos y polimorfismos del gen de la ECA. Se sometió a 83 sujetos (18 a 35 años), 46 hombres y 37 mujeres, a evaluaciones de capacidad vital forzada (CVF), presión inspiratoria máxima y presión espiratoria máxima (PIM-PEM). Posterior a esto, la genotipificación fue realizada por polimerase chain reaction (PCR) y electroforesis en gel de agarosa. Las variables fueron sometidas al análisis estadístico correspondiente según su distribución paramétrica, el nivel de significancia establecido fue un p<0,05. La distribución genotípica fue: Ins/Ins: 28 \%, Ins/Del: 62 \% y Del/Del: $19 \%$. Las mujeres homocigoto Ins, presentaron mayor PIM y PEM en modelos por genotipos $(\mathrm{p}=0,043 ; \mathrm{p}=0,0001$ respectivamente) y por dominancia $(\mathrm{p}=0,019 ; \mathrm{p}=0,0008$ respectivamente). La distribución genotípica y frecuencia alélica fue similar a la descrita anteriormente en población chilena. Además, las mujeres portadoras del alelo Ins, presentaron mayor PIM y PEM.

PALABRAS CLAVE: Presión inspiratoria máxima; Presión espiratoria máxima; Enzima convertidora de angiotensina.

\section{INTRODUCCIÓN}

La ventilación pulmonar es un proceso mecánico que depende de los músculos respiratorios, los cuales dirigen la expansión y retracción de la caja torácica (Ratnovsky et al., 2008). Se entiende entonces, que cada grupo muscular tiene funciones distintas y una estructura que soporta tal acción (Polla et al., 2004). Así existen características que se relacionan con el tipo, tamaño y capilarización de la fibra muscular (Luce et al., 1982), cualidades que pueden cambiar de un sujeto a otro, dependiendo de factores medio ambientales y genéticos y que finalmente expresaran menor o mayor capacidad de fuerza (Ostrander et al., 2009).

Específicamente, la fuerza muscular ventilatoria puede ser medida de dos formas: mediante una contracción involuntaria o una voluntaria. En esta última, se ana- liza la acción sinérgica de los músculos, tanto primarios como accesorios (American Thoracic Society/European Respiratory Society, 2002) y el valor obtenido es una aproximación a nivel de boca, debido a que en la práctica clínica es imposible medirla directamente (Gea \& Barreiro, 2008). El valor resultante tiene múltiples utilidades, donde la más estudiada es la determinación de cargas de entrenamiento tanto en el alto rendimiento como en cuadros patológicos. (American Thoracic Society/European Respiratory Society).

Por otra parte, se ha observado que la actividad enzimática y la producción de energía varían en un mismo grupo muscular entre distintos sujetos, lo que tendría relación con la predominancia de polimorfismos específicos

\footnotetext{
${ }^{1}$ Programa de Doctorado en Ciencias Morfológicas, Universidad de la Frontera, Chile.

${ }^{2}$ Facultad de Ciencias de la Salud, Departamento Ciencias del Movimiento, Universidad de Talca, Chile.

${ }^{3}$ Departamento de Kinesiología, Facultad de Ciencias de la Salud, Universidad Católica del Maule, Chile.
} 
MUÑOZ, C. R.; BECERRA, M. S.; \& PACHECO, V. A. Influencia del polimorfismo inserción/deleción (rs4646994) del gen de la enzima convertidora de angiotensina en la presión inspiratoria y espiratoria máxima de jóvenes chilenos sedentarios. Int. J. Morphol., 35(4):1254-1260, 2017.

(Caló \& Vona, 2008). En este contexto, el polimorfismo Inserción (Ins)/Deleción (Del) del gen de Enzima Convertidora de Angiotensina (ECA) se asocia a variaciones en la regulación del volumen sanguíneo, presión arterial y función vascular, factores que impactan en el rendimiento muscular y que explican en parte las diferencias entre distintos individuos (Becerra, 2014).

En detalle, la producción de Angiotensina II desde la I en el músculo esquelético, se debe a la actividad de la ECA en la membrana plasmática de este y en las células endoteliales de sus capilares, a través del funcionamiento del sistema renina angiotensina (Nguyen Dinh Cat \& Touyz, 2011). Sin embargo, la expresión de la ECA no es uniforme en todas las fibras musculares lo que indicaría que su expresión depende del metabolismo y bioquímica de las mismas (Cabello-Verrugio et al., 2015). Considerando esto, el polimorfismo Ins/Del también se ha asociado a cambios en el tipo de fibra muscular, con un aumento de fibras tipo I en los portadores del alelo Ins (Zhang et al., 2003).

Por tanto, el objetivo de este estudio es determinar las diferencias en el rendimiento muscular inspiratorio y espiratorio en un grupo de universitarios chilenos categorizados por su genotipo (polimorfismo rs4646994) del gen de la ECA.

\section{MATERIAL Y MÉTODO}

Sujetos. La muestra corresponde a sujetos de 18 a 35 años de edad, seleccionados por conveniencia. El grupo estuvo compuesto por 83 individuos: 46 hombres y 37 mujeres, estudiantes de la Universidad Católica del Maule, quienes aceptaron voluntariamente formar parte de este estudio y firmaron el consentimiento informado. Esta investigación fue aprobada por el Comité de Ética Científica de la Universidad Católica del Maule

Se excluyeron aquellos sujetos con antecedentes de enfermedad respiratoria crónica, hábito tabáquico activo, deformidad torácica, volumen espirado al primer segundo (VEF1) o flujo espiratorio forzado entre el 25 y $75 \%$ (FEF25-75) $<80 \%$ del predicho, sobre pesos (IMC $\geq 24,9$ $\mathrm{kg} / \mathrm{m}^{2}$ ), relación consanguínea con otro participante y deportistas.

Evaluación de la función pulmonar. Registrado la edad, talla y peso corporal, el sujeto debió permanecer sentado y relajado al menos unos 10 minutos previos a la evaluación. Las pruebas se realizaron en un pletismógrafo corporal marca Mediagraphics Modelo PlatinumElite DL®
Capacidad vital forzada (CVF): Se midió según la normativa de la American Society Thorax (ATS). De manera breve; el evaluado se colocó las pinzas nasales, ventiló a volumen corriente por cinco ciclos respiratorios a través del neumotacógrafo y se le indicó que realizará una maniobra inspiratoria máxima y posteriormente una espiración máxima forzada. Se seleccionó la mejor prueba de un mínimo de tres maniobras aceptables y reproducibles (Miller et al., 2005).

Medición de la presión inspiratoria y espiratoria máxima (PIM-PEM): Se midió según la normativa de la ATS. De manera breve, en el caso de la PIM el evaluado se colocó las pinzas nasales, ventiló a volumen corriente por cinco ciclos respiratorios a través del neumotacógrafo y se le indicó al sujeto realizar una espiración máxima, se bloqueó el neumotacógrafo y se solicitó una inspiración máxima contra la válvula cerrada. Para la PEM el evaluado se colocó las pinzas nasales, ventiló a volumen corriente por cinco ciclos respiratorios a través del neumotacógrafo y se le indicó al sujeto realizar una inspiración máxima, se bloqueó el neumotacógrafo y se solicitó una espiración máxima contra la válvula cerrada. En ambas, se seleccionó la mejor prueba de un mínimo de tres maniobras aceptables y reproducibles según normativa ATS (American Thoracic Society/European Respiratory Society).

\section{Análisis Genético.}

Extracción de ADN: el ADN genómico se extrajo de una muestra de 5 mililitros ( $\mathrm{mL}$ ) de sangre total anticoagulada con ácido etilendiaminotetraacético (EDTA) $(1 \mathrm{mg} / \mathrm{dl})$ y refrigerada a $4^{\circ} \mathrm{C}$, mediante el micrométodo de Yoduro de Sodio de Salazar et al. (1998). Brevemente, para lograr la lisis celular, a 300 microlitros $(\mathrm{mL})$ de sangre total se le adicionó igual volumen de yoduro de sodio $(\mathrm{NaI})$. Se agitó fuertemente y agregaron $600 \mathrm{~mL}$ de cloroformo/alcohol isoamílico (v/v, 24:1), para luego de centrifugar a $12.000 \mathrm{G}$ por 5 minutos, Luego se removió la fase superior y transferida a un microtubo estéril para adicionar $400 \mathrm{~mL}$ de isopropanol. Posteriormente, se centrifugamos a $12.000 \mathrm{G}$ por 5 minutos y lavamos el sedimento con isopropanol $37 \%$, para después centrifugar nuevamente a $12.000 \mathrm{G}$ por 5 minutos y eliminamos el sobrenadante, dejamos secar a temperatura ambiente, para finalmente resuspender el ADN en $100 \mathrm{~mL}$ de buffer Tris-EDTA (pH 8,0) e incubó a $56^{\circ} \mathrm{C}$ por 10 minutos, guardando los extractos de $\mathrm{ADN}$ a $-20^{\circ} \mathrm{C}$. La integridad del ADN extraído, se evaluó mediante electroforesis por 30 minutos a 100 volts, utilizando un gel de agarosa al $2 \%$, teñido con Gel Red® (Biotium, Hayward, CA, EEUU.), el producto fue visualizado utilizando un transluminador UV.

Diseño de partidores: se seleccionó como secuencia de interés la región comprendida entre la posición 11.332 y 11.643 
del gen de la ECA, lo que flanqueaba por ambos lados la región de Ins/Del del intrón 16. Para el diseño de los partidores se utilizó el software online Primer3 v0.4.0 (disponible en http://frodo.wi.mit.edu/). La secuencia de los partidores diseñados fueron las siguientes:

\section{P1: 5'-CTGGAGAGCCACTCCCATCCTTTCT-3' P2: 5'-GACGTGGCCATCACATTCGTCAGAT-3'}

Amplificación de ADN: la amplificación del material genético se realizó en un master mix con tampón de PCR $1 \mathrm{x}, 2 \mathrm{mM}$ de de cloruro de magnesio $(\mathrm{MgCl} 2), 0,2 \mathrm{mM}$ de dNTP, 0,5 U de Taq DNA polimerasa (Fermentas, Lituania), $200 \mathrm{nM}$ de cada partidor, $100 \mathrm{ng}$ de ADN y agua desionizada estéril para un volumen final de 25-20 mL. A continuación, los tubos fueron colocados en un Termociclador T100 (BioRad, EE.UU) y se programó el siguiente esquema de temperatura: una desnaturalización inicial a $95^{\circ} \mathrm{C}$ por 5 minutos, luego 32 ciclos de $95^{\circ} \mathrm{C}$ por 30 segundos, $60^{\circ} \mathrm{C}$ por 30 segundos de hibridación y $72^{\circ} \mathrm{C}$ por 30 segundos, para una extensión final a $72^{\circ} \mathrm{C}$ por 10 minutos. Se evaluaron los productos de la PCR mediante electroforesis en gel de agarosa al $2 \%$ teñido con Gel Red® (Biotium, Hayward, CA, EE.UU.) y visualizados en el transiluminador UV. Los resultados fueron fragmentos de 192 pares de base (pb) para el alelo Del y de $479 \mathrm{pb}$ para el alelo Ins. Entendiéndose el genotipo Ins/
Ins, la presencia de una única banda de $479 \mathrm{pb}$, genotipo Del/ Del la presencia de una banda de $192 \mathrm{pb}$ y el genotipo Ins/ Del a la presencia de ambas bandas de $192 \mathrm{pb}$ y $479 \mathrm{pb}$.

Análisis de datos. Los datos se tabularon y analizaron en los programas Microsoft Office Excel 2013 y GraphPad Prism 5® respectivamente. Los resultados se presentan como promedios \pm 1 desviación estándar. Para el análisis estadístico de las variables PIM y PEM, se determinó la normalidad de los datos a través de la prueba de Shapiro-Wilks, se usó la prueba t de Student o ANOVA según corresponda. Las mediciones que no cumplieron con una distribución paramétrica se analizaron con la prueba U de Mann-Whitney o Kruskal-Wallis respectivamente. Finalmente, se consideró un nivel de significancia de $\mathrm{p}<0,05$.

\section{RESULTADOS}

Características generales de la muestra: En la Tabla I se observa el comportamiento antropométrico y espirométrico de todos los participantes. El porcentaje del predicho evidencia normalidad para las variables de CVF, VEF1, FEF25-75 y flujo espiratorio máximo (FEM), para el sexo femenino y masculino respectivamente. Además cabe destacar, la dife-

Tabla I: Características generales de jóvenes sedentarios de la Universidad Católica del Maule, Chile.

\begin{tabular}{|c|c|c|c|}
\hline Variable & $\begin{array}{c}\text { Sexo Femenino (37) } \\
\text { Promedio } \pm \text { DS }\end{array}$ & $\begin{array}{c}\text { Sexo Masculino (46) } \\
\text { Promedio } \pm \text { DS }\end{array}$ & Valor $p$ \\
\hline Edad (años) & $21,81 \pm 1,39$ & $23,57 \pm 3,03$ & $0,001 * \S$ \\
\hline Peso (kg) & $59,63 \pm 8,79$ & $74,76 \pm 10,35$ & $0,0001 * \S$ \\
\hline Talla (m) & $1,61 \pm 0,06$ & $1,73 \pm 0,07$ & $0,0001 * \S$ \\
\hline IMC (kg/m²) & $23,01 \pm 2,84$ & $24,80 \pm 2,88$ & $0,004^{*}$ \\
\hline CVF (L) & $3,91 \pm 0,51$ & $5,46 \pm 0,58$ & $0,0001^{*}$ \\
\hline CVF (\% predicho) & $109,00 \pm 10,76$ & $110,07 \pm 8,99$ & - \\
\hline $\operatorname{VEF}_{1}(\mathrm{~L})$ & $3,37 \pm 0,38$ & $4,56 \pm 0,48$ & $0,0001^{*}$ \\
\hline VEF 1 (\% predicho) & $107,73 \pm 9,35$ & $107,26 \pm 8,19$ & - \\
\hline $\mathrm{VEF}_{1} / \mathrm{CVF}^{2}$ & $86,78 \pm 4,95$ & $83,85 \pm 4,74$ & - \\
\hline FEF $25-75$ (litros/segundos) & $3,81 \pm 0,68$ & $4,72 \pm 0,98$ & $0,0001^{*}$ \\
\hline FEF $25-75$ (\% predicho) & $101,03 \pm 18,07$ & $99,91 \pm 19,95$ & - \\
\hline FEM (L/s) & $7,59 \pm 1,07$ & $10,29 \pm 1,01$ & $0,0001^{*}$ \\
\hline FEM (\% predicho) & $114,68 \pm 15,84$ & $112,54 \pm 9,78$ & - \\
\hline PIM (-cmH2 & $118,62 \pm 35,40$ & $163,85 \pm 35,82$ & $0,0001^{*}$ \\
\hline PIM (\%predicho) & 92,00 & 126,00 & - \\
\hline $\operatorname{PEM}\left(\mathrm{cmH}_{2} \mathrm{O}\right)$ & $107,95 \pm 28,85$ & $172,54 \pm 38,83$ & $0,0001 *$ \\
\hline PEM (\%predicho) & 154,00 & 231,00 & - \\
\hline
\end{tabular}

DE: desviación estándar; IMC: índice de masa corporal; kg: kilogramo; L: litro; s: segundos; CVF: capacidad vital forzada; VEF1: volumen espiratorio forzado al primer segundo; VEF1/CVF: relación entre el volumen espiratorio forzado al primer segundo y la capacidad vital forzada; FEF 25-75: flujo espiratorio forzado entre el $25 \%$ y $75 \%$ de la capacidad vital forzada; FEM: flujo espiratorio forzado; PIM: presión inspiratoria máxima; cmH2O: centímetros de agua; PEM: presión espiratoria máxima; Prueba estadística: Prueba-t o Mann-Whitney ( §); (*)p<0,05. 
MUÑOZ, C. R.; BECERRA, M. S.; \& PACHECO, V. A. Influencia del polimorfismo inserción/deleción (rs4646994) del gen de la enzima convertidora de angiotensina en la presión inspiratoria y espiratoria máxima de jóvenes chilenos sedentarios. Int. J. Morphol., 35(4):1254-1260, 2017.

rencia significativa existente entre ambos sexos en todas las variables medidas, donde los hombres presentaron valores superiores. La distribución de los genotipos y las frecuencias alélicas de describen en la Tabla II, donde la muestra se encuentra en equilibrio de Hardy Weinberg.

Comportamiento por genotipos: en el sexo femenino, se observó un aumento significativo en la PIM $(p=0,043)$ y PEM ( $<<0,0001)$ del genotipo Ins/Ins sobre el Ins/Del y Del/ Del. Esta diferencia no se evidenció entre genotipos del género masculino (Tabla III).
Modelo de dominancia alélica Del: las mujeres de genotipo Ins/Ins presentaron mayores niveles de la PIM $(\mathrm{p}=0,019)$ y PEM ( $p=0,008)$ por sobre las mujeres agrupadas en los gentipos Del/Del+Ins/Del. Tampoco se evidenciaron diferencias por genotipo en el sexo masculino. (Tabla IV).

Modelo de dominancia alélica Ins: tanto en el sexo femenino como masculino, no se observó diferencia significativas en la PIM y PEM del genotipo Del/Del comparado con Ins/Ins-Ins/Del (Tabla V).

Tabla II. Distribución genotípica y alélica de jóvenes sedentarios en ambos sexos de la Universidad Católica del Maule, Chile .

\begin{tabular}{lcccc}
\hline & Frecuencia (37) & $\begin{array}{c}\text { Sexo Femenino } \\
\text { Equilibrio de } \\
\text { Hardy Weiberg }\end{array}$ & Frecuencia (46) & $\begin{array}{c}\text { Sexo Masculino } \\
\text { Equilibrio de } \\
\text { Hardy Weinberg }\end{array}$ \\
\hline $\begin{array}{l}\text { Genotipo } \\
\text { Ins/Ins }\end{array}$ & $0,297(11)$ & & $0,282(13)$ & \\
Ins/Del & $0,621(23)$ & $2^{2}=3,424 \mathrm{p}=0,064$ & $0,586(27)$ & $-2=1,872 \mathrm{p}=0,171$ \\
$\mathbf{D e l} / \mathbf{D e l}$ & $0,082(3)$ & & $0,132(6)$ & \\
Alelo & & & & \\
Ins & 0,608 & & 0,575 & \\
Del & 0,392 & & 0,425 & \\
\hline
\end{tabular}

Ins: inserción; Del: delesión; Test estadístico: Chi cuadrado, 1 gl. Número de individuos entre paréntesis.

Tabla III. Fuerza muscular ventilatoria y sus variables influyentes por genotipo, en jóvenes sedentarios de ambos sexos de la Universidad Católica del Maule, Chile.

\begin{tabular}{|c|c|c|c|c|c|c|c|c|}
\hline \multirow{3}{*}{ Variable } & \multicolumn{4}{|c|}{ Sexo Femenino } & \multicolumn{4}{|c|}{ Sexo Masculino } \\
\hline & \multicolumn{3}{|c|}{ Genotipo } & \multirow{2}{*}{ Valor } & \multicolumn{3}{|c|}{ Genotipo } & \multirow{2}{*}{ Valor $p$} \\
\hline & $\begin{array}{c}\text { DeVDel } \\
(\mathrm{n}: 3=8 \%)\end{array}$ & $\begin{array}{c}\text { Ins/Del } \\
(\mathrm{n}: 23=62 \%)\end{array}$ & $\begin{array}{c}\text { Ins } / \text { Ins } \\
(\mathrm{n}: 11=\mathbf{3 0} \%)\end{array}$ & & $\begin{array}{c}\text { DeVDel } \\
(\mathrm{n}: 6=14 \%\end{array}$ & $\begin{array}{r}\text { Ins/Del } \\
\text { (n:27=58 }\end{array}$ & $\begin{array}{c}\text { Ins/Ins } \\
(\mathrm{n}: 13=28 \%)\end{array}$ & \\
\hline Edad (años) & $21,83 \pm 1,40$ & $21,81 \pm 1,33$ & $21,82 \pm 1,54$ & 0,970 & $22,66 \pm 0,81$ & $24,11 \pm 3,68$ & $22,84 \pm 1,17$ & $0,855^{\ddagger}$ \\
\hline Talla (m) & $1,61 \pm 0,05$ & $1,61 \pm 0,06$ & $1,60 \pm 0,06$ & 0,703 & $1,74 \pm 0,03$ & $1,72 \pm 0,07$ & $1,73 \pm 0,08$ & $0,899^{*}$ \\
\hline Peso (kg) & $53,07 \pm 6,29$ & $60,33 \pm 9,04$ & $59,95 \pm 8,73$ & $0,994^{*}$ & $74,83 \pm 8,44$ & $73,15 \pm 9,73$ & $78,06 \pm 12,19$ & 0,176 \\
\hline PIM (-cmH2 & $106,33 \pm 20,1$ & $110,39 \pm 34,3$ & $139,18 \pm 34,1$ & $0,043 *$ & $167,50 \pm 29$ & $158,96 \pm 35$ & $172,30 \pm 40,35$ & 0,320 \\
\hline $\mathrm{PEM}\left(\mathrm{cmH}_{2} \mathrm{O}\right)$ & $89,67 \pm 36,07$ & $99,26 \pm 23,61$ & $131,09 \pm 25,4$ & 0,0001 & $174,83 \pm 34$ & $168,11 \pm 36$ & $180,69 \pm 45,94$ & 0,378 \\
\hline
\end{tabular}

Ins: inserción; Del: deleción; m: metros; kg: kilogramos; PIM: presión inspiratoria máxima; $\mathrm{cmH}_{2} \mathrm{O}$ : centímetros de agua; PEM: presión espiratoria máxima; Prueba estadística: ANOVA o Kruskal-Wallis ( $\ddagger) ;(*) p<0,05$.

Tabla IV. Fuerza muscular ventilatoria y sus variables influyentes agrupadas por Alelo Del dominante en jóvenes sedentarios de ambos sexos de la Universidad Católica del Maule, Chile.

\begin{tabular}{|c|c|c|c|c|c|c|}
\hline \multirow[t]{2}{*}{ Variable } & \multicolumn{2}{|c|}{$\begin{array}{c}\text { Sexo Femenino } \\
\text { Genotipo }\end{array}$} & \multicolumn{4}{|c|}{$\begin{array}{c}\text { Sexo Masculino } \\
\text { Genotipo }\end{array}$} \\
\hline & $\begin{array}{c}\text { Ins/Del-Del/Del } \\
(\mathrm{n}: 26=70 \%)\end{array}$ & $\begin{array}{c}\text { Ins/Ins } \\
(\mathrm{n}: 11=30 \%)\end{array}$ & & $\begin{array}{c}\text { Ins/Del-Del/Del } \\
\text { (n:33=71\%) }\end{array}$ & $\begin{array}{c}\text { Ins/Ins } \\
(\mathrm{n}: 13=\mathbf{2 9 \%})\end{array}$ & \\
\hline Edad (años) & $21,81 \pm 1,36$ & $21,82 \pm 1,54$ & 0,970 & $23,84 \pm 3,38$ & $22,84 \pm 1,17$ & $0,855^{\S}$ \\
\hline Talla (m) & $1,61 \pm 0,06$ & $1,60 \pm 0,06$ & 0,703 & $1,73 \pm 0,06$ & $1,73 \pm 0,08$ & $0,899^{8}$ \\
\hline Peso (kg) & $59,50 \pm 8,99$ & $59,95 \pm 8,73$ & $0,994 \S$ & $73,45 \pm 9,41$ & $78,06 \pm 12,19$ & 0,176 \\
\hline PIM (-cmH2 & $109,92 \pm 32,76$ & $139,18 \pm 34,14$ & $0,019^{*}$ & $160,51 \pm 33,96$ & $172,30 \pm 40,35$ & 0,320 \\
\hline $\operatorname{PEM}\left(\mathrm{cmH}_{2} \mathrm{O}\right)$ & $98,15 \pm 24,58$ & $131,09 \pm 25,43$ & $0,0008^{*}$ & $169,33 \pm 35,93$ & $180,69 \pm 45,94$ & 0,378 \\
\hline
\end{tabular}

Ins: inserción; Del: deleción; m: metros; kg: kilogramos; PIM: presión inspiratoria máxima; cmH2O: centímetros de agua; PEM: presión espiratoria máxima; Prueba estadística: Prueba-t o Mann-Whitney ( $),(*) p<0,05$. 
MUÑOZ, C. R.; BECERRA, M. S.; \& PACHECO, V. A. Influencia del polimorfismo inserción/deleción (rs4646994) del gen de la enzima convertidora de angiotensina en la presión inspiratoria y espiratoria máxima de jóvenes chilenos sedentarios. Int. J. Morphol., 35(4):1254-1260, 2017.

Tabla V. Fuerza muscular ventilatoria y sus variables influyentes agrupadas por Alelo Ins dominante en jóvenes sedentarios de la Universidad Católica del Maule, de ambos sexos.

\begin{tabular}{|c|c|c|c|c|c|c|}
\hline \multirow{3}{*}{ Variable } & \multirow{2}{*}{\multicolumn{2}{|c|}{$\begin{array}{c}\text { Sexo Femenino } \\
\text { Genotipo }\end{array}$}} & \multicolumn{4}{|c|}{ Sexo Masc ulino } \\
\hline & & & \multirow[t]{2}{*}{ Valor $p$} & \multicolumn{2}{|c|}{ Genotipo } & \multirow[t]{2}{*}{ Valor $p$} \\
\hline & DeVDel & Del/Ins-Ins/Ins & & DeVDel & Del/Ins-Ins/Ins & \\
\hline & $(n: 3=8 \%)$ & $(n: 34=92 \%)$ & & $(n: 6=13 \%)$ & $(n: 40=87 \%)$ & \\
\hline EDAD (años) & $21,67 \pm 1,15$ & $21,82 \pm 1,42$ & 0,856 & $22,67 \pm 0,82$ & $23,70 \pm 3,22$ & $0,697^{\S}$ \\
\hline TALLA (m) & $1,61 \pm 0,05$ & $1,61 \pm 0,06$ & 0,894 & $1,74 \pm 0,04$ & $1,73 \pm 0,08$ & $0,905^{\S}$ \\
\hline PESO (kg) & $53,07 \pm 6,29$ & $60,21 \pm 8,81$ & $0,159^{\S}$ & $74,83 \pm 8,44$ & $74,75 \pm 10,69$ & 0,985 \\
\hline $\mathrm{PIM}\left(-\mathrm{cmH} \mathrm{H}_{2} \mathrm{O}\right)$ & $106,33 \pm 20,13$ & $119,71 \pm 36,43$ & 0,425 & $167,50 \pm 29,10$ & $163,30 \pm 37,01$ & $0,619^{\S}$ \\
\hline $\operatorname{PEM}\left(\mathrm{cmH}_{2} \mathrm{O}\right)$ & $89,67 \pm 36,07$ & $109,56 \pm 28,21$ & 0,188 & $174,83 \pm 34,61$ & $172,20 \pm 39,82$ & 0,878 \\
\hline
\end{tabular}

Ins: inserción; Del: deleción; m: metros; kg: kilogramos; PIM: presión inspiratoria máxima; cmH2O: centímetros de agua; PEM: presión espiratoria máxima; Prueba estadística: Prueba-t o Mann-Whitney ( §); (*)p $<0,05$

\section{DISCUSIÓN}

El objetivo de la presente investigación fue comparar el rendimiento muscular inspiratorio y espiratorio según alelo y polimorfismos del gen de la ECA en jóvenes sedentarios. Previo a esto se determinó la distribución genotípica y frecuencia alélica del polimorfismo de este gen. La muestra se encontró en equilibrio de Hardy Weinberg y concuerda con resultados locales previos (Jalil et al., 1999; Rosales et al., 2009).

Determinado el equilibrio de la muestra en estudio, el análisis de nuestros datos evidenció una conducta normal de la PIM y PEM. Los valor obtenidos fueron significativamente mayores en hombres sobre las mujeres, asimismo la PEM fue mayor a la PIM. Este comportamiento concuerda con lo reportado por Morales et al. (1997), Simões et al. (2010) y Araújo et al. (2012) y se debe a la mayor talla, peso y masa muscular en el sexo masculino.

Específicamente, al comparar el rendimiento muscular inspiratorio y espiratorio entre genotipos del gen de la ECA, los datos obtenidos mostraron mayores valores de la PIM y la PEM en las participantes homocigotas Ins. En experiencias previas Dimitriou et al. (2010a), determinaron en 110 infantes asistidos por ventilación mecánica, un aumento significativo de la ECA circulante en el genotipo Del/ Del sobre el Ins/Del e Ins/Ins, además de una relación significativa mayor del genotipo Del/Del con la PIM. Paralelamente, en el mismo año, el mismo grupo de investigadores (Dimitriou et al., 2010b) analizó a 132 lactantes en ventilación mecánica, en este grupo encontró una disminución significativa del índice presión-tiempo de la musculatura inspiratoria en el genotipo Ins/Ins con respecto al Ins/Del y
Del/Del. Cabe destacar que en ambos estudios la PIM mostró un valor mayor en el genotipo Ins/Ins en comparación al Ins/Del y Del/Del, sin embargo esta diferencia no fue significativa. Esto difiere de los resultados que se obtuvieron en nuestra investigación, donde sí se evidenciaron estas diferencias en el sexo femenino. Creemos que esto se puede deber a la estructura del diafragma en lactantes, al respecto se sabe que este músculo pasa por un proceso madurativo donde existen cambios morfológicos, así en edades tempranas la distribución de las fibras tiende al equilibrio: fibras tipo I: $40 \%$; tipo IIa: $30 \%$ y tipo IIb: $30 \%$ (Orliaguet et al., 2004). En este contexto, si observamos las fibras de contracción rápida logran un $60 \%$ del total, a diferencia del adulto donde las fibras de contracción lenta suman el $60 \%$ del total del músculo. Esto, sumado a los antecedentes que indican un mayor desarrollo de fuerza asociado al alelo Del, explicaría la diferencia en los rendimientos de las presiones a favor de este alelo en lactantes.

Por otra parte la relación existente entre el alelo Ins, ejercicio aeróbico y estructura de los músculos ventilatorios, debemos considerar tres puntos importantes: i) la principal característica de los músculos ventilatorios es la pequeña área de sección cruzada de sus fibras $(50 \%$ menos de isoformas de miosina) en comparación a los músculos de las extremidades para una misma red capilar (Mizuno, 1991), ii) el número de capilares que rodea a cada fibra es similar para los distintos grupos musculares esqueléticos, hecho importante considerando la relación inversa que existe entre actividad enzimática oxidativa y área de sección cruzada (Polla et al.) y iii) la baja distancia existente entre la fibra muscular y el vaso sanguíneo en las fibras del diafragma, 
potencia su capacidad oxidativa. Creemos que estas características respaldan el aumento significativo de la PIM y la PEM obtenida en los homocigotos Ins.

Sabido esto, debemos considerar la acción de la ECA y su función en el músculo esquelético, específicamente Dietze \& Henriksen (2008), describen que al inicio del ejercicio la contracción de fibras lentas y su rápida oxidación, son generadas por el sistema nervioso colinérgico. Este incremento bioenergético estimula la producción de kininas e inhibe la actividad de la ECA en el tejido endotelial del vaso sanguíneo, reduciendo la generación de Angiotensina II. En este contexto, la kinina unida a los receptores b2 en el endotelio capilar y sarcolema de la fibra muscular aumentan la concentración intracelular de calcio, activando las enzimas cicloxigenasa y oxidonitrosintasa, facilitando la transmisión de óxido nítrico y prostaglandinas. Esto genera permeabilidad del capilar, vasodilatación y el tránsito de glucosa a la miofibrilla (Dietze \& Henriksen; Becerra). En síntesis, la estructura del musculo ventilatorio sumado a la actividad de la ECA en el mismo, apoya el aumento significativo de la PIM y la PEM encontrada.

Por último, consideramos importante destacar que las diferencias significativas obtenidas en las mayores presiones ventilatorias asociadas al genotipo Ins/Ins, sólo se produjo en el sexo femenino. Con respecto a esto, Minson et al. (2000) demostraron en jóvenes sanas, que en la fase lútea de su periodo menstrual existe un aumento significativo de estradiol y progesterona, una menor actividad nerviosa simpática y resistencia vascular muscular. Los investigadores atribuyen estos cambios a la asociación existente entre estradiol y óxido nítrico (Sudhir et al, 1996). Por lo que la mayor disponibilidad de óxido nítrico asociado al sexo femenino contribuiría a explicar la diferencia entre ambos sexos.

En relación a ciertas limitaciones referentes a esta investigación, no se registró la fase del ciclo menstrual, ni el uso de anticonceptivos, aspectos relevantes en la comprensión del rendimiento muscular ventilatorio por sexo, según lo argumentado en nuestra discusión. La morfología indica que los músculos ventilatorios están conformados mayormente por fibras tipo I. En este contexto la prueba de presión máxima debería ser acompañada por una prueba de resistencia muscular ventilatoria (Ratnovsky et al.).

En conclusión, la frecuencia del genotipo en el sexo femenino y masculino fue Ins/Ins: 29-28 \%, Ins/Del: 62-58 $\%$ y Del/Del: $9-14 \%$ respectivamente, coincidiendo con lo reportado para la población chilena. Además se observó una mayor PIM y PEM en sujetos de sexo femenino homocigotas para el alelo Ins del gen de la ECA.
MUÑOZ, C. R.; BECERRA, M. S.; \& PACHECO, V. A Influence of the polymorphism insertion / deletion (rs4646994) of the angiotensin converting enzyme (ACE) gene on Maximum Inspiratory and Expiratory Pressure of Chilean sedentary youth. Int. J. Morphol., 35(4):1254-1260, 2017.

SUMMARY: Gene expression can impact muscle performance. In this aspect genetic polymorphism of the Angiotensin Converting Enzyme (ACE), depending on its insertion or deletion can strengthen different muscle qualities. Similarly, if we consider ventilation as a vital process, it would be important to research whether or not, there is an influence of this polymorphism on the muscles that perform such an important function. The aim of this study was to determine the inspiratory and expiratory muscle performance according alleles and polymorphisms of the ACE gene. We subjected 83 individuals (18-35 years), 46 men and 37 women, to forced vital capacity evaluations, maximum inspiratory pressure and expiratory pressure. Genotyping was subsequently performed by polymerase chain reaction (PCR) and agarose gel electrophoresis. The variables were subjected to appropriate statistical analysis by parametric distribution, the significance level was set at $\mathrm{p}<0.05$. The genotype distribution was: Ins/Ins: $28 \%$, Ins/Del: $62 \%$ and Del/Del: $19 \%$. Women homozygous Ins, exhibited a higher maximum inspiratory pressure and expiratory pressure in models for genotypes $(\mathrm{p}=0.043 ; \mathrm{p}=0.0001$ respectively $)$ and for dominance $(\mathrm{p}=0.019$; $\mathrm{p}=0.0008$ respectively). The genotype distribution and allele frequency was similar to that described above, in Chilean population. Furthermore, women carrying the Ins allele had a higher maximum inspiratory pressure and expiratory pressure.

KEY WORDS: Maximum inspiratory pressure; Maximum expiratory pressure; Angiotensin converting enzyme.

\section{REFERENCIAS BIBLIOGRÁFICAS}

American Thoracic Society/European Respiratory Society. ATS/ERS Statement on respiratory muscle testing. Am. J. Respir. Crit. Care Med., 166(4):518-624, 2002.

Araújo, P. R.; Resqueti, V. R., Nascimento Junior, J.; Carvalho, L. de A.; Cavalcanti, A. G.; Silva, V. C.; Silva, E.; Moreno, M. A.; Andrade, A. de F. \& Fregonezi, G. A. Reference values for sniff nasal inspiratory pressure in healthy subjects in Brazil: a multicenter study. J. Bras. Pneumol., 38(6):700-7, 2012.

Becerra, M. S. Polimorfismo inserción/deleción del gen de la ECA y su influencia en el rendimiento físico. REEM, 1(2):7-14, 2014.

Cabello-Verrugio, C.; Morales, M. G.; Rivera, J. C.; Cabrera, D. \& Simon, F. Renin-angiotensin system: an old player with novel functions in skeletal muscle. Med. Res. Rev., 35(3):437-63, 2015.

Caló, M. C. \& Vona, G. Gene polymorphisms and elite athletic performance. J. Anthropol. Sci., 86:113-31, 2008.

Dietze, G. J. \& Henriksen, E. J. Angiotensin-converting enzyme in skeletal muscle: sentinel of blood pressure control and glucose homeostasis. $J$. Renin Angiotensin Aldosterone Syst., 9(2):75-88, 2008.

Dimitriou, G.; Papakonstantinou, D.; Stavrou, E. F.; Tzifas, S.; Vervenioti, A.; Athanassiadou, A. \& Mantagos, S. Angiotensin-converting enzyme gene polymorphism and respiratory muscle function in infants. Pediatr. Pulmonol., 45(12):1233-9, 2010a. 
MUÑOZ, C. R.; BECERRA, M. S.; \& PACHECO, V. A. Influencia del polimorfismo inserción/deleción (rs4646994) del gen de la enzima convertidora de angiotensina en la presión inspiratoria y espiratoria máxima de jóvenes chilenos sedentarios. Int. J. Morphol., 35(4):1254-1260, 2017.

Dimitriou, G.; Papakonstantinou, D.; Stavrou, E. F.; Tzifas, S.; Vervenioti, A.; Onufriou, A.; Athanassiadou, A. \& Mantagos, S. Association of circulating angiotensin converting enzyme activity with respiratory muscle function in infants. Respir. Res., 11:57, 2010b.

Gea, J. \& Barreiro, E. Update on the mechanisms of muscle dysfunction in COPD. Arch. Bronconeumol., 44(6):328-37, 2008.

Jalil, J. E.; Piddo, A. M.; Cordova, S.; Chamorro, G.; Braun, S.; Jalil, R.; Vega, J.; Jadue'P, L.; Lavandero, S. \& Lastra, P. Prevalence of the angiotensin I converting enzyme insertion/deletion polymorphism, plasma angiotensin converting enzyme activity, and left ventricular mass in a normotensive Chilean population. Am. J. Hypertens., 12(7):697704, 1999.

Miller, M. R.; Hankinson, J.; Brusasco, V.; Burgos, F.; Casaburi, R.; Coates, A.; Crapo, R.; Enright, P.; van der Grinten, C. P.; Gustafsson, P.; Jensen, R.; Johnson, D. C.; MacIntyre, N.; McKay, R.; Navajas, D.; Pedersen, O. F.; Pellegrino, R.; Viegi, G.; Wanger, J. \& ATS/ERS Task Force. Standardisation of spirometry. Eur. Respir. J., 26(2):319-38, 2005.

Minson, C. T.; Halliwill, J. R.; Young, T. M. \& Joyner, M. J. Influence of the menstrual cycle on sympathetic activity, baroreflex sensitivity, and vascular transduction in young women. Circulation, 101(8):862-8, 2000.

Mizuno, M. Human respiratory muscles: fibre morphology and capillary supply. Eur. Respir. J., 4(5):587-601, 1991.

Morales, P.; Sanchis, J.; Cordero, P. J. \& Díez, J. L. Maximum static respiratory pressures in adults. Reference values for a Caucasian Mediterranean population. Arch. Bronconeumol., 33(5):213-9, 1997.

Nguyen Dinh Cat, A. \& Touyz, R. M. A new look at the renin-angiotensin system--focusing on the vascular system. Peptides, 32(10):2141-50, 2011.

Orliaguet, G.; Riou, B. \& Leguen, M. Postnatal maturation of the diaphragm muscle: ultrastructural and functional aspects. Ann. Fr. Anesth. Reanim., 23(5):482-94, 2004

Ostrander, E. A.; Huson, H. J. \& Ostrander, G. K. Genetics of athletic performance. Annu. Rev. Genomics Hum. Genet., 10:407-29, 2009.

Polla, B.; D'Antona, G.; Bottinelli, R. \& Reggiani, C. Respiratory muscle fibres: specialisation and plasticity. Thorax, 59(9):808-17, 2004.

Ratnovsky, A.; Elad, D. \& Halpern, P. Mechanics of respiratory muscles. Respir. Physiol. Neurobiol., 163(1-3):82-9, 2008.

Rosales, A.; Jaramillo, P.; Lanas, C.; Lanas, F. \& Salazar, L. A. Polimorfismo Ins/Del del gen de la enzima convertidora de angiotensina-I en individuos chilenos con enfermedad coronaria documentada por angiografía. Biomed. Sci., 1(1):20-7, 2009.

Simões, R. P.; Deus, A. P.; Auad, M. A.; Dionísio, J.; Mazzonetto, M. \& Borghi-Silva, A. Maximal respiratory pressure in healthy 20 to 89 yearold sedentary individuals of central São Paulo State. Rev. Bras. Fisioter, 14(1):60-7, 2010.

Sudhir, K.; Jennings, G. L.; Funder, J. W. \& Komesaroff, P. A. Estrogen enhances basal nitric oxide release in the forearm vasculature in perimenopausal women. Hypertension, 28(3):330-4, 1996.

Zhang, B.; Tanaka, H.; Shono, H.; Miura, S.; Kiyonaga, A.; Shindo, M. \& Saku, K. The I allele of the angiotensin-converting enzyme gene is associated with an increased percentage of slow-twitch type I fibers in human skeletal muscle. Clin. Genet., 63(2):139-44, 2003.

\author{
Dirección para Correspondencia: \\ Rodrigo Muñoz Cofré \\ Doctorado en Ciencias Morfologicas \\ Universidad de La Frontera \\ Temuco \\ CHILE
}

E-mail:b.munoz13@ufromail.cl

Recibido :10-08-2017

Aceptado:10-10-2017 